OPEN ACCESS

Edited by: Barbara Gemmill-Herren,

Prescott College, United States

Reviewed by:

Manuel González De Molina, Universidad Pablo de Olavide, Spain David Rose, University of Reading, United Kingdom

*Correspondence: Chris Maughan

chris.maughan@coventry.ac.uk

Specialty section:

This article was submitted to Agroecology and Ecosystem Services,

a section of the journal

Frontiers in Sustainable Food Systems

Received: 19 October 2020 Accepted: 21 January 2021

Published: 18 February 2021

Citation:

Anderson CR and Maughan C (2021)

"The Innovation Imperative": The Struggle Over Agroecology in the International Food Policy Arena. Front. Sustain. Food Syst. 5:619185 doi: 10.3389/fsufs. 2021.619185

\section{"The Innovation Imperative": The Struggle Over Agroecology in the International Food Policy Arena}

\author{
Colin R. Anderson and Chris Maughan* \\ Centre for Agroecology, Water and Resilience, Coventry University, Coventry, United Kingdom
}

As the gravity of the global social and ecological crises become more apparent, there is a growing recognition of the need for social transformation. In this article, we use a combination of narrative case study and discourse analysis to better understand how transformative concepts, such as agroecology, are shaped as they as they enter mainstream discursive arenas. We probe the different characteristics of the "innovation frame" and how they qualify and give meaning to agroecology. Our case study narrates the recent emergence of agroecology in the UN space and its relationship to the discursive frame of innovation. We then undertake a systematic discourse analysis of comments provided in an online consultation process on the "Agroecology and Other Innovations" report by the 2019 High-Level Panel of Experts (HLPE) in the World Committee on Food Security. We examine how different actors positioned themselves vis-a-vis the innovation frame and we analyse the discursive strategies used to advance particular political agendas. Our analysis reveals three primary sub-frames within the innovation frame (Evidence; Technology; Rights) which were deployed by both proponents and detractors of agroecology. We focus on the notion of social agency, and its different presentations, within the three sub-frames which raises a number of problematics of the innovation frame, not only for agroecology, but for sustainability transformations more widely.

\footnotetext{
Keywords: agroecology, innovation, food policy, agricultural policy, technology, critical discourse analysis, FAO (Food and Agriculture Organization)
}

\section{INTRODUCTION}

For at least a decade, proponents of agroecology have been hammering loudly at the gates of international policy arenas. In essence, their claim has been that agroecology has the potential to address the myriad and intertwined crises of food sustainability and social justice. Agroecology's move into the mainstream has been glacial, punctuated by numerous small victories-for example the FAO's symposia on agroecology beginning in 2014. However, the response by proponents of conventional agriculture has consistently been that agroecology is unrealistic and unviable (Bellwood-Howard and Ripoll, 2020). In an attempt to rebut these criticisms, civil society groups-mainly via the Civil Society Mechanism (CSM) of the Committee on World Food Security (CFS) - requested the production of a report on agroecology from the High Level Panel of Experts (HLPE), a respected body designed to provide independent, evidence-based analysis, and advice to the CFS. This report would, as the authors themselves described it, gather evidence and make recommendations to inform "major transformation of whole food systems" (HLPE, 2019). 
While the request was eventually granted-ratified during the 44th congress of the CFS, 2017-it didn't pass without a struggle, with numerous proponents of industrial agriculture insisting that the focus of the report be broadened to include more than just "agroecology," but also "other innovations" for sustainability. It is this seemingly innocuous addition that is the subject of this paper. Why was the inclusion of "other innovations" so important to those routinely opposed to the transformational implications of agroecology? And what impact did it have on a report that many hoped would mark the belated entry of agroecology into the agricultural policy mainstream?

This article approaches these questions by focusing on discourse and its importance in shaping sustainability transitions. We focus on "innovation" as a discursive frame long in circulation in debates about social change and how it is being deployed in the more recent global discourse on agroecology. What kind of discursive maneuvers-or what we outline below as "framings"-are being used to influence rapidly emerging discourses of agricultural and agroecological innovation? Conversely, how can certain framings end up limiting "transformational" potential; that is, the ability of systems to move in the direction of justice and sustainability? To analyse the relationship between the innovation frame and agroecology, we explore the process behind the HLPE report (2019) mentioned above, in particular the public consultation which helped to shape its eventual content.

\section{Sustainability Transitions and Discourse}

While the technical and market-based dimensions of sustainability transitions have long been the focus of academic research, it is increasingly recognized that deep transformations to systems of production and reproduction are urgently needed (Scoones et al., 2015; O’Brien, 2016; Mummery and Mummery, 2019). In contrast to transition, a transformative approach centers the dynamics of governance, control and power as the key determinants of social-technical change (Stirling, 2014; Anderson et al., 2019).

Power is about more than wielding physical or material resources, it is also enacted and reproduced through discourse as words, images, and ideologies (Foucault, 1969). In regards to agroecology, the importance of discursive "disputes" or the "terrain of ideas, of theoretical constructs" is recognized as a critical factor in shaping the potential of agroecology (Fuchs and Glaab, 2011; Giraldo and Rosset, 2018, p. 546). In this case, discourse represents, "an ensemble of ideas, concepts and categories [expressed in language] through which meaning is given to social and physical phenomena, [and] which is produced and reproduced through an identifiable set of practices" (Hajer and Versteeg, 2005, p.175). However, discourse is not simply a matter of describing and representing social life, it is also closely related to power as it is socially constructed, shaping behavior, language, and thought of those who participate in it.

When discourses "enter and achieve salience or dominance in particular social fields or domains," they inform new ways of acting, identifying and organizing (Fairclough, 2013, p.77, 358). Discourse thus plays an important role in providing legitimacy for some transition pathways, while delegitimizing, deemphasizing or re-casting others (Fuchs and Glaab, 2011; Geels et al., 2014; Montenegro de Wit and Iles, 2016). A particularly striking example of this can be seen in the prominent positioning of "feed the world" narratives in legitimizing expansions to existing industrialized production, and de-legitimizing ecologically productive, but lower-yielding production (Fouilleux et al., 2017; Anderson et al., 2020a). Through their discursive power, actors influence the perceptions and normative assumptions of definitions that are deployed in political arenas, which shapes the resulting policies, actions, norms, and procedures (Hajer and Versteeg, 2005). Our approach here offers insight not only on a highly contested discourse of agroecology-and in particular its development within a mainstream or hegemonic discursive arena-but more broadly in the ways in which such counter-hegemonic language in sustainability transitions is itself countered, reframed, and neutralized.

\section{Framing Agroecology and Innovation}

Agroecology has been routinely framed by its proponents as an alternative paradigm to the industrial food and agricultural regime (Nyeleni, 2015; Rosset and Altieri, 2017; Anderson et al., 2019; González de Molina et al., 2019). Yet, agroecology does not have a single fixed meaning and it has been argued there are multiple "agroecologies" (Méndez et al., 2013) as it is re-signified (Rivera-Ferre, 2018) and co-produced (Loconto and Fouilleux, 2019) by different actors with different values, intentions and worldviews (van Hulst et al., 2020). Indeed, agroecology, to some, is an ambitious and integrative set of principles intended to govern systems-level sustainability transitions. To others, agroecology is being cast as a small (minor) subset of production practices alongside many other options. Yet still to others, agroecology has been described as an outdated, impractical and even dangerous approach because it undermines the centrality of yield and profit as the object of agricultural development (Tom, 2020).

The recent global attention to agroecology in academia, policy-making, and amongst practitioners and social movements has simultaneously generated excitement and anxiety amongst proponents of a transformative agroecology. On the one hand, many view the institutional uptake of agroecology and its mainstreaming as a vital part of the transition to sustainable food systems. On the other, history has demonstrated how once radical and transformative frameworks for agriculture have become deformed and denuded of their transformative potential as they become adopted and incorporated into existing markets, policy-frameworks, and as powerful actors step in to discursively and materially control the dynamic (Levidow et al., 2014; Laforge et al., 2016; Giraldo and McCune, 2019; Anderson et al., 2020b). For example, the involvement and incorporation of organic agriculture into corporate-led chains has been derided for undermining the values and the transformative potential that the pioneering organic movement was founded on (Guthman, 2004).

In this article, we engage with the complexities and problematics of institutionalizing transformative concepts like agroecology, focusing particularly on what we refer to as the "innovation frame" and how it is being mobilized by different 
actors in relation to agroecology. Innovation has been used over time as a way of thinking about societal change, and in regard to sustainability and agriculture more specifically (El Bilali, 2019). The term was first popularized by Joseph Schumpeter, who defined it as, "doing things differently" (Schumpeter, 2005 [1939], p. 84); indeed, this simple framing might explain how innovation has become a ubiquitous concept in mainstream development models. However, whilst the term remains at the center of debates today about how society changes, it has continued to signal predominantly market-led and technological pathways for social change. As Pansera and Owen (2018: p.xxi) suggest, innovation "has the potential [to develop] a hegemonic framing that emphasizes features typical of neoliberal agendas such as competitiveness, ownership, productivity, efficiency, and marketorientation." Indeed, leading economic thinkers have even begun to frame it in terms of the "innovation imperative" (OECD, 2015), elevating the fetish for novelty and technological "progress" into an existential ultimatum familiar in developmental discourse: modernize or disappear.

In the EU, the "Innovation Principle"-though slightly less insistent than the OECD's innovation "imperative" formulation (OECD, 2015) - has been criticized for its use in circumventing environmental and health safeguards in favor of market-ready innovations (Anderson, 2020). A growing number of voices, including those adopting post-development, feminist and critical agrarian studies perspectives (Kothari et al., 2019) have worked to unveil the colonial nature of the modernist assumptions of change that underpin terms like innovation. From these perspectives, innovation has been used to advance a linear conceptualization of change (toward a singular modernity), where things that are innovative are only valued as such when they pull in the same direction as technological "progress" and wealth accumulation.

In agriculture, the innovation, the innovation frame has been criticized for its preoccupation with increasing productivity, profits, and economic growth (Quist et al., 2013). An emergent literature has begun to examine the effects of a new generation of agricultural technology, sometimes referred to as "4th industrial revolution (4IR)" technologies, suggesting their claims to social and ecological benefits may be unsubstantiated (Miles, 2019), that their negative impacts are downplayed (Barrett and Rose, 2021), and may ultimately be incompatible with agroecological principles, especially the "undesirable side effects [... of digital technologies [on] rural employment and rural-urban migration" (Klerkx and Rose, 2020).

Despite the intimate link between these technologies and the innovation frame, the general response of these authors has been to call for a re-purposing of innovation, toward more "responsible" and "inclusive" innovation systems. In doing so, they follow a number of scholars and activists from different backgrounds calling for a similar re-framing of innovation to mobilize it as a tool for pursuing the social, ecological and economic dimensions of sustainability transitions. There have been calls for a normative basis to direct what type of innovation should be promoted to foster transition toward sustainable food systems (El Bilali, 2018) and explorations of the potential of inclusive innovation (Levidow and Papaioannou,
2018), grassroots innovation (Seyfang and Smith, 2007), social innovation (Baker and Mehmood, 2015; Rover et al., 2016), retro innovation (Stuiver, 2006), coupled innovation (Meynard et al., 2017) and agroecological innovations (Uphoff, 2013; Berthet et al., 2015). In the field of agroecology, many have engaged with these traditions to modify or qualify innovation in some way to prioritize the agency of marginalized groups, to assert the importance of incorporating environmental and social aspects as a key goal of innovation and more generally to be much more inclusive of the wider range of activities that drive change in food systems (Rover et al., 2016; López-García et al., 2018; El Bilali, 2019; Schiller et al., 2019; Marchetti et al., 2020).

Despite this growing literature, innovation is very seldom historicised within the genealogy of capitalism, and can easily be repurposed unwittingly or disingenuously to contest capitalism itself. In an attempt to redress this, our article examines the discursive maneuvers of differently positioned actors in relation to innovation and agroecology, while bearing in mind this political-historic genealogy of innovation. Our article presents a discursive analysis to understand what the innovation framing "does" in debates on the governance of food and agriculture, and particularly for radical proposals for transformation such as agroecology. Can innovation be recast, as some have hoped, to bring it in line with the principles of agroecology? Or will innovation continue to foreground productivism and accumulation ahead of urgent social and environmental concerns?

\section{METHODOLOGY}

This study focuses on a particular discursive arena-The debates on agroecology and innovation in the United Nations. A discursive arena is an analytic boundary deployed in processes of deliberation and negotiation. It involves demarcating an arena and a process within which different views are performed, so that meaning, and understanding can be harvested for the purposes of analysis. In forums for public participation, for example, this analysis is often directly linked to policy-making processes. Indeed, high level policy documents have provided the focus of numerous studies of food and agricultural policy (Barrett and Rose, 2021; Lajoie-O'Malley et al., 2020; Maughan et al., 2020). In contrast, this study focusses on the deliberation of differently positioned actors within the discursive arena, rather than the policy outcomes themselves. The construction of discursive arenas is a political process where decisions on which views are included, and which perspectives and knowledge are harvested and prioritized, are made by those able to wield or gain power within the domain. Our approach is intended as a way to make legible the disparate and contrasting forces convened within policy-making processes.

The UN space is important because of its role in advising governments, directing resources, and the high visibility of UN debates and programs on the world scene. For these same reasons, the FAO is also a contested space where many actors jostle to shape the food and farming discourse. In order to contextualize, and to interrogate the innovation frame within this 
discursive arena, our study weaves together a combination of case study and critical discourse analysis. The narrative case study helps us first to understand how the particular discursive arena has been constructed and what the political dynamics behind its construction have been. We have already explained above in the introduction how the process of selecting the title for the HLPE report was marked by a conflict over the inclusion of the word "innovation." The frame analysis of the comments from the public consultation on this report, which we embed within this narrative case study of agroecology in the UN, offers a snap-shot of the different and contesting voices often hidden in published policy documents. Mapping the dynamics of this contestation, we argue, will be vital for understanding the broader struggle to determine what innovation is for and whose interests it serves.

\section{Participant Observation and Narrative Case Study}

The first part of our analysis (presented in the first and final section of our results) reviews and analyzes the progression of agroecology in the U.N. system over the last decade-particularly the FAO and the HLPE of the CFS, culminating in a recent report on "agroecology and other innovations" (which is the focus of the second section of our results). The FAO is an international intergovernmental institution, funded and governed by nationstates and provides basic research, information gathering and dissemination, formulation of policy recommendations, technical assistance, and government consultation. The goals of FAO are to: "Help eliminate hunger, food insecurity, and malnutrition; Make agriculture, forestry, and fisheries more productive and sustainable; Reduce rural poverty; Enable inclusive and efficient agricultural and food systems; Increase the resilience of livelihoods to threats and crises; Establish technical quality, statistics, and cross-cutting themes" (FAO, 2020). It is a highly influential forum where discursive processes are highly visible, and translated into budgetary outcomes in FAO and indirectly in its influence on national policy-making.

In order to construct this narrative account, we draw from participant observations in the process, analysis of related UN literature, web-analysis, and a small number of interviews with key informants involved in the UN process. This narrative case study helps not only to contextualize the discursive dynamics at play in the UN policy arena (especially the types of actors and their different positionalities), but also to connect it to external events and trends. To this end, after the frame analysis we return to the narrative account in the following section, offering a brief examination of the final report as well as a number of other salient policy events. A full analysis of the final report was beyond the scope of this article, as it was our intention to prioritize not the policy publications (which get a lot of attention) but the often-hidden, largely implicit and typically highly divergent positions taken up by participants during the policy consultation and formulation processes.

\section{Critical Discourse Analysis of HLPE Report on Agroecology and Other Innovations}

The second component of our analysis (presented in the second section of our results) uses critical discourse analysis of 141 comments provided as a part of the official online consultation for the HLPE report "Agroecology and Other Innovations" (HLPE, 2019). The High-Level Panel of Experts for Food Security and Nutrition (HLPE) acts as the sciencepolicy interface of the UN Committee on World Food Security (CFS). The CFS is the foremost inclusive and evidence-based international and intergovernmental platform for food security and nutrition (FSN). The HLPE produces scientific, policyoriented reports, including analysis and recommendations, serving as a comprehensive and evidence-based starting point for policy debates at the CFS. The HLPE draws together existing research and knowledge to produce global, multi-sectoral, and multi-disciplinary analysis in high profile reports. HLPE studies combine scientific knowledge with experiences from the ground, through its consultative process. The topics and scope of the CFS are determined by the HLPE steering committee that start with a political question and request formulated by the CFS. The 14th report, on "Agroecological Approaches and Other Innovations" (HLPE, 2019), is the focus of this article.

The HLPE runs two open consultations per report: first, on the scope of the study; second, on a V0 "work-in-progress" draft. Consultations enable the HLPE to better understand the issues and concerns, and to enrich the knowledge base, including social knowledge, thriving for the integration of diverse scientific perspectives and points of view. Our analysis focuses on the publicly available comments that were submitted as a part of this second consultation. The HLPE committee incorporates the input from these consultations into a final draft which is subjected to external scientific peer-review. HLPE reports are then published and form the basis of policy discussions and debates in the CFS.

In response to the online consultation on the zero draft of the HLPE report on Agroecological Approaches and Other Innovations, 141 comments were submitted. These comments were provided-in many cases collaborativelyby representatives from 37 different countries. According to the HLPE's own synthesis of the report (HLPE, 2018), "7 contributions come from national governments, 32 from civil society and NGOs, 23 from the private sector, and 57 from academic or research institutes." Despite this institutional spread, there was a clear regional bias with 50 percent of the contributions come from Europe, 21 percent from North America, and only 12 percent from Latin America and the Caribbean, 8 percent from Asia, and 6 percent from Africa. The remaining 2 percent from the Near East and South-West Pacific. Overall, 26 percent of the contributions come from "developing countries."

Critical discourse analysis refers to a broad church of approaches to analyzing language which address its involvement in the production and reproduction of power (Fairclough, 2013). Methodologically, CDA is intended to interrogate discursive practices to understand how they reproduce and extend particular social and political relations by "normalizing" certain assumptions and delegitimizing others. Our study investigated these discursive strategies and interactions by differently positioned of actors around the role of agroecology as a framework for sustainability transitions in food systems.

In order to help make sense of the different ways that agroecology is being constructed, we employ the concept of 
framing. Frame analysis is an approach to discourse analysis used to understand how discourses are constructed to support particular ideological positions or worldviews (Steinberg, 1998). A frame is an interpretation that simplifies and condenses "the world out there" (Snow and Benford, 1992, p.137) and offers a way of understanding and projecting a particular position or concept. Thus, in any discursive arena where actors are debating or invoking agroecology, multiple frames are advanced by actors from different positions of power through an oftenimplicit political process of contestation. The discursive arena is thus co-constructed between different actors with differential power vying to frame and shape discourse (in our case about sustainability transitions) to promote justifications, prognoses, policies, and courses of action that align with their own interests. Frame analysis provides an approach that can make sense of these (often implicit) discursive dynamics, framing processes, and power relations.

We used n NVivo Qualitative Data Analysis software (V12) to code the 141 official comments in the HLPE process on the zero draft. All submissions were spot-checked and any that offered only minor or insubstantial inputs (e.g., tweaks in wording), that were duplicate entries or those that copied and pasted generic text (e.g., previous publications) were eliminated. The remaining 102 responses were coded to identify emergent themes. The two authors each open coded the documents, generating analytical memos focusing particularly on data that reflected the relationship between agroecology and innovation. The coding, content and analytical memos were then reconciled through dialogue between the researchers. As a part of this iterative process, the larger set of initial openended codes were iteratively combined and hierarchized into three main subframes. These sub-frames were constructed to understand the contested views on innovation as they relate to agroecology, and to better understand how each sub-frame is normalized and rationalized by actors. The contours of the three main sub-frames (Table 1) are articulated in Part $\mathrm{B}$, below, presenting their main dimensions illustrated with emblematic quotes.

\section{RESULTS AND DISCUSSION}

\section{Part A: Case Study: The Progression of Agroecology and Innovation in FAO and the HLPE}

While elements and practices of agroecology had been present in the FAO for many years, it was since $\sim 2010$ when civil society, in concert with a handful of supportive governments, began to push for agroecology in FAO in a substantial way. From 2015 to 2019, the FAO engaged in a Global Dialogue to examine the potential role of agroecology as a pillar of agricultural development (Loconto and Fouilleux, 2019). At the same time, support for agroecology was growing and being advocated for by some member states (the "Friends of Agroecology"). However, these efforts to elevate agroecology in FAO were opposed by some member states (Canada, Australia, Argentina, and especially the USA) who felt agroecology did not
TABLE 1 | Original codes and how they were grouped under final three "sub-frames."

\begin{tabular}{|c|c|c|}
\hline Supportive of innovation & $\begin{array}{l}\text { Sub- } \\
\text { frame }\end{array}$ & $\begin{array}{l}\text { Critical of conventional notions of } \\
\text { innovation }\end{array}$ \\
\hline $\begin{array}{l}\text { - Conventional and } \\
\text { standardized metrics should } \\
\text { be used to assess the } \\
\text { effectiveness of innovations } \\
\text { - Non-scientific knowledge is } \\
\text { less reliable } \\
\text { - Economic productivity and } \\
\text { yield should be prioritized }\end{array}$ & 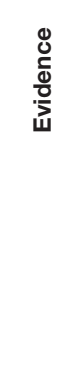 & $\begin{array}{l}\text { - New and more holistic measures of } \\
\text { ecological and social impact should } \\
\text { be developed } \\
\text { - Agroecology is only full known } \\
\text { when incorporating diverse ways of } \\
\text { knowing and thus measuring } \\
\text { - Knowledge needs to be evaluated } \\
\text { in situ } \\
\text { - Simultaneously prioritizes } \\
\text { ecological, economic and } \\
\text { social productivity }\end{array}$ \\
\hline
\end{tabular}

- Novel technology is the primary driver of social change

- Novel technologies will likely benefit farmers

- Novel technologies are preferred by youth

- Novel technologies can "feed the world"
자 - Industrial/novel technologies can create many negative outcomes
- Social innovations are as important as technological ones
- Innovations should be developed at all levels, especially in situ
- Farmers and citizens are innovators (i.e., knowledge producers)

- Farmers should have the right to choose from the full range of agricultural products and innovations

- Intellectual property rights of technology developers should be prioritized

promote their own national interests or the vision of agricultural development they project into the world. Despite this opposition, the International Year of Family Farming in 2014 created a political opportunity for FAO to bolster the theme of agroecology (Loconto and Fouilleux, 2019).

The proposal was to hold a symposium on agroecology followed by a series of regional seminars. However, the approval was conditional with the USA insisting that:

1. The symposium had to be a technical symposium meaning it would have no formal political weight in FAO.

2. Speakers were also told they could not include certain words in the official program: international trade policies, genetically modified organisms (GMOs), or even the use of the term "food sovereignty," which were viewed as too political and threatening (Giraldo and Rosset, 2018).

3. Whatever was organized for agroecology, a parallel process had to be organized for biotechnology (Source: interview).

Thus, FAO set forth to organize a two-stream process. An initial international symposium was organized in Rome for both agroecology (2014) and biotechnology (2016) resulting in final reports for each (FAO, 2016). Follow-up regional consultations were planned in both streams. 
TABLE 2 | Timeline of key FAO moments regarding agroecology and innovation. Source: interviews, FAO (2018).

\begin{tabular}{|c|c|c|}
\hline & Agroecology & Biotechnology \\
\hline & \multicolumn{2}{|c|}{$\begin{array}{l}\text { (2013-2016) Civil society contests biotech. Agroecology } \\
\text { beginning to gain ground in FAO }\end{array}$} \\
\hline Kick off symposium & $\begin{array}{l}\text { 1st International Symposium } \\
\text { on Agroecology (September } \\
\text { 2014) }\end{array}$ & $\begin{array}{l}\text { 1st International Symposium } \\
\text { on the Role of Agricultural } \\
\text { Biotechnologies in } \\
\text { Sustainable Food Systems } \\
\text { and Nutrition (February } \\
\text { 2016) }\end{array}$ \\
\hline $\begin{array}{l}\text { Regional } \\
\text { multi-stakeholder } \\
\text { meetings }\end{array}$ & $\begin{array}{l}7 \text { on Agroecology in: Brasilia } \\
\text { (June 2015), Dakar } \\
\text { (November 2015), Bangkok } \\
\text { (November 2015); La Paz } \\
\text { (September 2016), Kunming } \\
\text { (August 2016), Budapest } \\
\text { (November 2016); Tunis, } \\
\text { (November 2017) }\end{array}$ & $\begin{array}{l}2 \text { on Biotechnology in: } \\
\text { - Asia \& Pacific (September } \\
\text { 2017) } \\
\text { - Sub-saharan Africa } \\
\text { (November 2017) }\end{array}$ \\
\hline Closing Symposium & $\begin{array}{l}\text { 2nd International Symposium } \\
\text { on Agroecology (April 2018) }\end{array}$ & $N / A$ \\
\hline $\begin{array}{l}\text { Innovation } \\
\text { symposium }\end{array}$ & $\begin{array}{l}\text { International Symposium on Ir } \\
\text { (November 2018) }\end{array}$ & nnovation for Family Farming \\
\hline $\begin{array}{l}\text { HLPE Report } \\
\text { in CFS }\end{array}$ & $\begin{array}{l}\text { (2018-2019) HLPE Report on } \\
\text { Other Innovations }\end{array}$ & Agroecology and \\
\hline
\end{tabular}

Seven agroecology regional consultations were then scheduled between June 2015 and August 2016 in all regions (Table 2) with the exception of North America, culminating in a final report that synthesized all of the debates across the meetings (FAO, 2018). Despite plans for a similar number of regional meetings on biotechnology, only two were ultimately organized. At the first regional meeting held in September 2017 in Asia/Pacific, social movements participated and used the forum to "ask inconvenient questions" (source: interview) and to raise criticisms of biotechnology in the public. Evidently concerned by these developments, the FAO biotech process and the remainder of the regional conferences were canceled (Source: Interview).

In 2018, a second international forum was held in Rome on agroecology as the culmination of the Global Dialogue on Agroecology where over 900 people attended and participated in the launch of FAO's "scaling up initiative." The chair's summary, read at the end of the meeting, contained an emphasis on "transformation" and the rights and agency of food producers. But the summary was later censored and cut back (Loconto and Fouilleux, 2019). Meanwhile, proponents of biotech within FAO regrouped and started a process focusing instead on "innovation," organizing an international "Agricultural Innovation for Family Farmers" in November 2018 (source: Interview). In this context, agroecology was discussed, alongside other emerging technologies, including big data analytics, automation, and GMOs.

This brings us to the episode with which we opened this article: the parallel process, pushed by civil society in the World Committee on Food Security, to initiate a High Level Panel of Experts (HLPE) report on Agroecology.
While proponents of agroecology had long-advocated for an HLPE report that focused on agroecology, this was again obstructed by proponents of industrial agriculture (source: interview). Eventually, with enough pressure, an HLPE report on agroecology was confirmed, but with the concession that the report couldn't only be about agroecology, but rather about Agroecology and "Other Innovations."

Thus, both in this HLPE report, and through the mutation of the biotechnology process into an innovation process in $\mathrm{FAO}$, innovation functions as a frame to bring agroecology and contrasting (and arguably antithetical) approaches such as biotechnology into a common frame. This innovation "framing" is thus the focus of the next section where we report on our analysis of three innovation sub-frames we identified within the HPLE consultation process.

\section{Part B: Frame Analysis of HLPE Consultation Process The Evidence Sub-frame: Innovation as Valid Through Measurement}

Decisions about how and what we measure shape material realities. Like frames, they simplify and condense information, foregrounding particular dimensions as indicators of success and failure, and ignoring or downplaying others. Accordingly, there was a strong focus on measuring and evidencing the impacts of innovation across the comments. Given HLPE's stated aim, to provide "a comprehensive overview of the [...] best available scientific evidence" (HLPE, 2019), this emphasis on evidence is not a surprise. While an appeal to evidence is often presented as a way to objectively value and compare different innovations, a closer review of the comments demonstrates that its use can also limit the horizon of what is considered "legitimate" when using the dominant methods and tools of documenting evidence.

The respondents who were more skeptical of agroecology often pointed out a shortfall in acceptable evidence, claiming, "the innovations as described are underrepresented in an essential area, measurement" [Donald Moore, Global Dairy Platform]. Others appeared to endorse the value of alternative measures of evidence such as for well-being, only to reject them in favor of established economic metrics:

While the well-being perception of local communities is an important subjective indication of sustainability, objective economic factors, including household income and variability, more clearly demonstrate contributions to the sustainability of communities and the agricultural system. [Kristen Hendricks, USDA]

In doing so, this commentator drew from familiar arguments about the relative immeasurability of social, cultural, political and many ecological outcomes, in contrast to those that measure economic outcomes and yield. The same respondent complained that, "It is not clear where the draft report stops being scientific and starts being political" [Kristen Hendricks, USDA], disparaging the impacts of innovation that cannot be "objectively" measured. At times, the same respondent demonstrated a clear distaste for the draft document, and the "description of agroecology" 
contained within it, suggesting that it was "aspirational, idyllic, utopian, and not based on reality" (Ibid.). Whatever the legitimacy of the respondents' concerns about evidence gaps, the dismissive language is noteworthy. This discursive maneuver disingenuously nods to the importance of social outcomes, such as well-being, but excludes the social and political from formal consideration (and evidencing) because they are immeasurable by conventional standards.

Elsewhere, more subtle discursive maneuvers were at play that-when read carefully — revealed the prioritization given to the profitability of agricultural innovations. One particularly interesting example stated, "With appropriate consideration given to potential consequences and trade-offs, responsible research should be the foundation of practices recognized as genuinely innovative." [Brian Baldwin, IAFN]

On the surface, the comment appears to be sympathetic to an integrative approach to measuring innovation, positioning "responsible research" as the "foundation" of what is "genuinely innovative"-yet the claim is subtly caveated. The organizing principle here is in fact the "appropriate consideration given to potential consequences and trade-offs" [emphasis added]. If read in terms of earlier stated interests of "objective economic factors," this must be seen as synonymous with the profit motive of the agricultural private sector, rather than, for example, long-term environmental impacts or human rights infringements. As such, this is an example of neoliberal double-speak-cementing the primacy of the market in the delivery of social goods while appearing to defer to responsible research.

A similarly subtle sleight of hand is visible again when the same respondent writes: "We encourage the HLPE to broaden the thinking on innovation from the current draft which demonstrates an extremely narrow focus placed solely on social process of innovation." [Brian Baldwin, IAFN]. While disagreements routinely orbit around questions of salience like this-one person's broadening of focus, is another's narrowing-such statements bring to the fore the predominance of market logic in shaping our understanding of what innovation is for. While critics of agroecology sometimes argued for the breadth and depth of conventional measures, this was often in contradiction with their recommendations. Take, for example, discussion around farmer livelihoods. Conventionally this is measured in narrow market terms like GDP or household income, in a way that can side-line measures of other important factors such as mental health and ecological resilience. It was clear that for some respondents this is the way that it should stay. One respondent, for example, argued that, "Simply put, it is critical to recognize that farmers throughout the world are business owners", downplaying their roles as ecological stewards, community members, and knowledge producers. "Simply put" is indeed telling here, as such a framing forecloses a consideration of farmers as anything other than passive participants in economic exchange, who, as the same respondent put it, "need to be provided with all of the means, in terms of both information and physical tools, that could support their objectives" [Donald Moore, Global Dairy Platform]. This framing is crucial, appearing on the surface to be about farmer agency (i.e., by supporting "their objectives") while on the other had constructing their role as recipients of innovation. Here, farmers are provided with "all of the means" but are excluded from the innovation process, thereby limiting their political and practical horizons.

By contrast, some respondents were keen to point out that conventional economic measures were only one concern among many, and called for greater, "reflection on the role indicators play in the design and implementation of policies" [Katia Roesch, Coordination Sud]. Advocates of social innovation, for example, could be characterized by their attempt to reorient-even "widen"-innovation processes to include social needs rather than solely market outcomes. This was reflected in calls to move, "toward holistic agroecological indicators such as nutritional value, ecosystem biodiversity and services, climate change resilience, and farmer innovation." [Fabio Leippert, Biovision].

While proponents of agroecology often acknowledged shortcomings in the agroecology evidence base, this was often presented as a frontier to be overcome rather than a fatal flaw as, "[one] of the missing pieces is the inadequate level of research to assess the impact of AE on women's economic and social empowerment." [Tontie Binado, ActionAid]. In a similar vein, another respondent claimed that, "More nuanced and in-depth exploration is needed to elucidate how knowledge is linked to and permeates agroecological practice; and the unique ways in which agroecology spreads and scales out knowledge and innovation." [Faris Ahmed, USC Canada].

While agroecology is hardly a new field of study, its calls for a "fundamental shift" in the way our food systems are measured (IAASTD, 2009) have long been hamstrung by a significant underinvestment in agroecological research e.g., (Pimbert and Moeller, 2018; Moeller and Devlaux, 2020). As one respondent illustrates, such "paucity of data [creates] a bias [toward] the economic benefits of industrial agriculture [...] The data paints a biased picture and does not take into account local results in terms of food security." [Katia Roesch, Coordination Sud]. Accordingly, many respondents to the consultation clearly conceived of agroecology as an ongoing project with evidence still to be gathered and emphasized the need for new measures capable of capturing the multiple benefits arising from agroecological systems.

In contrast to respondents who used the innovation frame to validate generalizable science and standardized indicators were those pointing out the importance of local and indigenous knowledge. Such perspectives raise important questions about the epistemological compatibility such perspectives with an indicator- and science- led approaches to innovation. As one respondent argued,

\begin{abstract}
Local and traditional knowledge is often not documented in peerreviewed studies, and much richness and local experience salient to these issues is lost. We suggest that a greater proportion of case studies and research from civil society organisations is included to balance the scientific "way of knowing" especially since agroecology seeks to foreground the local and traditional knowledges of food producers and consumers. [Vanessa Black, Biowatch].
\end{abstract}

As this respondent suggested, the appeal to standardized indicators as the measure of quality and worth can easily 
erase local, traditional, and farmer knowledge and the benefits that agroecological approaches have in ways that are highly specific to place. Advocates of agroecology have historically resisted such generalized approaches, citing the links between processes of universalisation and standardization and efforts to advance imperialist modes of "development," and such views were strongly represented in the consultation.

\section{The Technology Sub-frame: Innovation as Technology} The second major sub-frame concerns "innovation as technology," in particular the dominant conception of technology as novel techniques, methods and tools, often packaged as machines or technologies deployed at the farm level. From the labor-saving technologies of the industrial revolution, to the use of robotics and genetic modification in contemporary systems, agricultural technologies have consistently stirred controversy. Have such technologies made life easier for farmers, eaters, and society as a whole? have they generated more and complex problems in the long-term? The innovation discourse has largely emerged alongside such controversies, being often seen as synonymous with "top down," or "externally introduced technologies" (Joly, 2018). Despite efforts to develop broader conceptualisations of innovation that incorporate social processes, politics and other conceptual features, there remains a strong tendency to reduce innovation to uptake of novel technologies.

Unsurprisingly, the HLPE consultation surfaced familiar tensions in its consultation, with respondents positioning themselves differently in relation to technology by either(a) endorsing the existing repertoire of industrial agricultural technology as a key driver in beneficial changes in the agricultural sector, or (b) problematising top-down approaches to innovation as technology, either with reference to the destructiveness of existing technologies, or by calling for a broader conception of what innovation and innovative technology is and the benefits it should produce.

A prominent feature of the innovation as technology frame were claims that existing technologies were being unfairly criticized. As one respondent puts it, "ISF regrets the negative tone that this paragraph takes on the technology and innovation that has so greatly benefited food security and nutrition in developed countries during the past decades" [Helene Guillot, ISF]. Here and elsewhere, pro-technology respondents argued as if controversies around certain technologies had already been settled. As another respondent put it, "The UN has already [...] formally supported the need for convergence of all the available technologies and their use in integrated solutions that are able to address local needs and societal requirements". [Brian Baldwin, IAFN]. Here, technologies are framed as indispensable tools for meeting "needs," though needs which are apparently defined from above, which pacify participants (by offering "food security" rather than meaningful involvement in decision-making), and which are vaguely defined ("societal requirements"). By contrast, any consideration of these technologies' long-term impacts, or of affected communities' collective rights to technology sovereignty are omitted.
As with the previous sub-frame, critics of agroecology sometimes pointed to the emotional and unreliable nature of oppositions to technology driven approach. As one respondent put it, the draft, "fails to consider unjust fears of technology and emotion-driven policy-making that is not based on science" [Brian Baldwin, IAFN]. In doing so, the respondent surfaced a long-running conflict between "precautionary" vs. "risk-based" approaches to technology development. Generally speaking, this debate revolves around how to deal with the lack of knowledge about the impact of technological or procedural change. Whereas the precautionary principle states that the "the proponent of an activity, rather than the public, should bear the burden of proof" (Brand, 2010), a risk-based approach contends that evidence for hazards be established before restrictions are imposed (Garnett et al., 2018). While "risk" might reasonably be seen as synonymous with (rather than opposed to) "precaution," its use by organizations like the "European Risk Forum" (ERF) has illustrated its capacity to undermine the precautionary principle. The ERF's support of the "innovation principle," for example, has been seen by some as a way to push through controversial innovations (Anderson, 2020), prioritizing the "needs" of the sector to bring new technologies to market, over those of the long-term risks of those technologies to human and planetary health.

While some respondents called for a commitment to, "the Precautionary Principle" as the only way to, "assess the consequences of innovation" [Sarah Schneider, MISEOR], "precaution" and "risk" also illustrate the confusing ways such debates play out in the innovation discursive arena. In this case, "risk" is deployed in an apparently misleading way to cover the less palatable interests of the private sector. Similar examples appear elsewhere, to such an extent that an increasingly shared discursive territory emerges, with key words and phrases bridging, hybridizing, and borrowing across the technophilictechnocritic spectrum. For instance, as one contributor suggests,

New plant varieties created through methods of biotechnology and novel breeding techniques have the opportunity to provide growers with varieties that are adapted to their local conditions and resilient to a changing climate. [Brian Baldwin, IAFN]

Rather than emphasizing productivity gains, this respondent draws on the urgency of climate change and local conditionsmore readily associated with the agroecology and food sovereignty movements-to justify controversial and unpredictable proprietary technologies. This discursive overlapping repeats a familiar pattern of capture by the agricultural mainstream, aimed at absorbing the challenges which come from those advocating more radical transfers of power.

Another key area of shared language could be seen in the appeal to a number of marginalized stakeholders often associated with agroecology, such as women, smallholder farmers, and especially youth. Referring to the latter, respondents noted technology's role in attracting and empowering such groups to view agriculture as a legitimate option for their futures. Such an empowering process could not exist, so one respondent claimed, 
if innovation were to be seen as "largely limited to the adoption of historical practices" [Donald Moore, Global Dairy Platform]. Another respondent highlighted the role of "external inputs," claiming that they,

could mean relief from backbreaking labor, particularly for the poor, women and children on whom this task often falls based on "local knowledge and traditional". From a social just [sic] perspective this needs to be recognized. [Gloria Jaconelli, CropLife International].

Again, not only do we see the invocation of marginalized groups to justify externally introduced technology, but the simultaneous attempt to discredit "local" and "traditional" technologies and knowledges. Agroecology-in its affirmation of traditional technologies, local knowledge, and its aim to gain autonomy from expensive proprietary technologies and external inputs-is characterized not only as inefficient or outdated, but also "socially [un]just." In line with the idea of the "innovation imperative," top-down technological extension is advanced here not only as a rational choice, but as a moral imperative: to refuse such technologies is to abandon the poor and marginalized to destitution and even death. This caricature of agroecology as wholly anti-technology, when combined with this moral imperative, is a powerful though unrepresentative claim against agroecology and its proponents. As described in the following paragraphs, proponents of agroecology generally advocate for appropriate technology and science in agroecological systems, and for the importance of civil society governance in weighing the impacts, advantages and disadvantages of technology in the long term social, economic and ecological wellbeing of rural and urban people.

As one might expect, there were also many respondents who were critical of a technology-led approach, pointing to the longterm risks that certain technologies pose to food producers and society. Genetic modification was frequently cited and identified as problematic, with one respondent calling for the, "HLPE not to use this subject to advance GMOs [...], new and under-researched gene editing technologies, [...] CRISPR and allied technologies', concluding that 'this is not what "innovation" is." [Rahul Goswami, Center for Environmental Education, Himilayas]. Other respondents pointed to the toxic and unknown impacts of GMOs, arguing that nature should not be privatized but to rather treat, "seeds and biodiversity as a commons that cannot be enclosed by any form of IPRs." [Laura Gutierrez Escobar, Grupo Semillas, Colombia]. These perspectives further contested the idea that such technologies were not only legitimate alternatives to agroecological innovations, but compatible with them. After dissecting biofortified food and GMO to reveal the risks and drawbacks of these approaches, one respondent suggested that

the title of the report to be modified, since it leads to the understanding that "other innovations for sustainable agriculture and food systems that enhance food security and nutrition" have agroecological character, which is not the case. [Carolina Alzate Gouzy, Núleo de Agroecologia e Produção Orgânica UnB, Brazil]
Such contestations reflected the subtle way in which the innovation frame offers a "menu of options" which are all vaguely presented as viable and desirable, and therefore difficult to refuse (Van Dyck et al., 2019). Some participants were well aware of the implications of such a framing, arguing that innovation in agricultural technologies is far from an exclusively modern or industrial phenomenon; on the contrary, agroecological innovations could be seen as historically integral to placespecific co-evolution of social and ecological systems. As one commentator put it,

It should be acknowledged that agricultural innovation has been taking place for thousands of years...and has continuously adapted to changing social and ecological developments.... This evolving relationship of coproduction underpins agroecology and differentiates it from "other innovations." [Anisah Madden, AFSA]

While clearly problematising the simplistic relation between technology and beneficial social and environmental outcomes, such respondents were not necessarily "anti-technology." Indeed, this same respondent acknowledged "the use of digital technologies to reduce Food Loss and waste is a positive application", before reminding us that "this is not the only application of big data and digitalisation of the food chain' and calling for 'more critical investigation and analysis." [Anisah Madden, AFSA]. In short, those critical of technology, could consistently be seen to call for a revised understanding of technology and innovation, one which began by "decoupling" technology from the "concept of innovation" and recoupling it to a series of other social and environmental issues, such as "the right to adequate food and the pursuit of food security and nutrition." [Stefano Prato, CSM]. At the heart of these claims, as we will explore in the next section, is a call for a re-integration of the innovation processes-arguably so long a feature of agricultural development-back into the lives of those most affected by them.

\section{The Rights Sub-frame: Innovation as a Path to Fulfill Human Rights}

While many respondents addressed the issue of rights in some way, much like in other sub-frames, there were contrasting views on the meaning of rights and how they should be secured. At root, a distinction could be made between arguments that foregrounded individualistic economic rights on the one hand, and collective and political rights on the other. The former placed an emphasis on the markets as the most empowering mechanisms of social change and on the rights of individuals to choose access technologies and innovations. Here, the emphasis is on the notion of "choice," indicating that end-users should have the freedom to choose from all available technologies. As one response illustrates,

taking the example of improved varieties, which are the result of technology and innovation, ISF would like each farmer around the world to have the possibility to make an informed choice about which seed will best suit their personal circumstances. [Helene Guillot, ISF] 
As we have seen already, farmers are sometimes framed as primarily business owners, and the right to access-or choosefrom all available agricultural innovations was repeatedly claimed to be crucial to ensuring farmer livelihoods. Occasionally, such rights were framed in terms of "property rights,"

ISF emphasizes that effective intellectual property (IP) protection stimulates breeders to invest in the development and delivery of new varieties to provide farmers with the widest possible choices for productivity and success, thereby ensuring global food security. [Helene Guillot, ISF]

As with the technology sub-frame, the main thrust here was a call to protect, not the rights of vulnerable peoples directly, but to ensure the property rights of technology developers so that a wider range of improved products can be made available to farmers. This reflects an approach that underlines technology developers as having exclusive rights to own, control and profit, and the ability of individual farmers to have access to the use of all available technologies as an inalienable right. Again, justification for this power is given, not purely in economic terms, but that doing so would help to deliver wider social goods, like "global food security."

In contrast to arguments in favor of individual economic rights, were those of collective political rights, such as the "right to food" and food sovereignty (defined as the right of all peoples "to define their own food and agriculture systems" (Nyeleni Movement for Food Sovereignty, 2007). The "stronger" formulations of these arguments were articulated in ways which highlighted the distorting impact of the innovation discourse on human and environmental rights. Some actively attempted to de-emphasize innovation altogether, claiming:

Rights is not another innovation. It is important to ground the entire analysis within the rights-based mandates of the CFS. Currently, Right-based innovations are included alongside other production systems, when they do not belong in that analysis. Rights provide a fundamental base that underpin all of SFS and FSN. [Maywa Montenegro, ARC]

In doing so, these respondents illustrated the profound divisions in approach to innovation which, as the above quotation suggests, can easily flatten out important political dynamics, making human rights or agroecology appear like "options," rather than the moral foundations on which the socio-technical world ought to be built. Indeed, as another respondent put it,

\section{Innovations should be considered as creative responses to challenging conditions and/or the mix of processes and practices that promote transitions to a new desired state. In the CFS context, the only innovations that should be considered are those whose explicit motive is the realization of the right to adequate food and the pursuit of food security and nutrition. [Stefano Prato, CFS]}

Whether the rights in view were economic or political in focus, all contributors were interested in how actors could be included in the innovation processes and systems, reflecting the now-prominent concern in the innovation discourse generally
(Cf. OECD and "inclusive innovation"). However, differing conceptions of rights highlight deep-rooted divisions in the way that participation is imagined. On the surface there appeared to be similarities - for example, even those conceptualizing farmers as primarily "business owners," also argued that "decision-making for farmers should remain local." [Donald Moore, Global Dairy Platform]-yet these decision-making processes were invariably contained within markets. Where political and collective rights were put forward, they tended to be much further reaching in scope, framing farmers not only as "beneficiaries," but active participants in defining what innovation means in each context. For example,

Any assessment rubric for successful innovation should therefore be democratically defined, co-developed, and led by rural peoples' ecological knowledge and practices. Rather than treating smallholder farmers as beneficiaries of aid, they should be seen as experts with knowledge that is complementary to formalized expertise. [Anisah Madden, AFSA]

Such arguments could be distinguished in the way they understood innovation not as a "thing" whose value is implicit, but as a process whose aims must be continually assessed and revised, especially by those most affected by their potential impacts. Though both conceptions effectively forego a detailed definition of what innovation is, the reasons for this are quite different. Those using it to defend individualistic economic rights appears do so in a vague way: like Schumpeter, innovation is simply "doing things differently" as a way of bringing products to market, whatever their impacts. By contrast, those working on a basis of collective rights defer definition in an apparently deliberate way: what innovation is must be collectively and "democratically defined" and "co-developed" in specific contexts, and in close articulation with the social and environmental dynamics of that place. This market- vs. people-led distinction is often buried behind the seductive shimmer of "novel" technological innovation. In this discursive arena, we argue, the contrast between these two positions was brought powerfully to the fore, especially by those calling for us to reclaim and revise our understandings of what innovation means and what it is for.

\section{THE FINAL HLPE REPORT AND BEYOND The Final HLPE Report - A Shift in Framing}

From December 2018 to February 2019, the HLPE committee considered and incorporated the views expressed through the online consultation on the V0 draft. These were used to develop a V1 draft which was then sent for expert peer review, revised again, and ultimately launched on July 3, 2019 in at the FAO Headquarters in Rome. While we did not conduct a full analysis of the report-focussing instead on the often-hidden discursive dynamics that played out through the individual interventions in the consultative process-some points are worth noting as they relate to the three innovation sub-frames. Perhaps the biggest shift between the V0 and V1 drafts involved a repositioning of the issue of human rights and the emphasis on the issue of agency. While in the V0 draft, "rights based approaches" were positioned 
alongside eight other proposed "approaches to innovation" in sustainable food systems, including "climate smart agriculture" and "agroforestry." In the final version, the authors shifted the framing of the report, positioning human rights as a master frame and demoting both agroecology and innovation, claiming "This report starts from the recognition of human rights as the basis for ensuring sustainable food systems" [emphasis added]. This could be seen in the report's call to add "the emerging concept of "agency" as a fifth pillar of food and nutrition security to capture the importance of people's participation in decisionmaking." Such a move highlights not only a strengthening of the rights agenda in this arena, but also the attempt to counter the tendency of the innovation frame to flatten out policy discourse to make things like human rights equivalent to-in some cases co-terminus with-commercial choice and economic freedoms. Further, the report also placed the notion of "transformation" more centrally in final report, a point that has since been contentious with governments who are wary of the ramifications and commitments demanded by a rights-based framing of transformation. Here, again, adopting an innovation framing is much safer and non-threatening for governments.

The report's approach to technology also registered an attempt to respond to challenges made in the consultation phase. Within its recommendations was the urge to move beyond the "technological paradigm" which has "become increasingly incompatible with present and future expectations." Elsewhere, however, there was still evidence of top down approaches to "technology transfer mechanisms" which, while focussed on "technologies in agroecological and other innovative approaches," were still framed in terms of technology "adoption [...] by farmers/producers" rather than prioritizing innovation with these actors.

\section{After the Scaling Agroecology Process and the HLPE Report}

Ultimately, the efforts in the 5 years leading up to the launch of the HLPE report marked a substantial opening for agroecology. On the one hand, there is evidence that the re-framing efforts have watered down and depoliticized the radical agroecology being advanced by social movement actors (Giraldo and Rosset, 2018). On the other, actors in the UN discursive space, including in the final HLPE report, have pushed the boundaries, arguing for food system transformation, and framing of agroecology in a way that reflects many of the tenets of food sovereignty (Loconto and Fouilleux, 2019). This has also resulted in deliberate promotion of specific transformative elements in civil society and government spaces, leading to further research, advocacy, and programming at multiple levels. The FAO's Scaling Up Initiative has included the allocation of institutional budget in FAO to agroecology with dedicated staff, the development of a global tool for monitoring agroecology (called TAPE), amongst other concrete benefits.

That said, it is also true that these successes have also met a significant backlash by proponents of the status quo and there are now moves to attack, discredit, and exclude agroecology in the UN system. Firstly, the US government continued to obstruct the HLPE report after its release, blocking the utilization of the findings in the Food Systems and Nutrition Guidelines and also objecting to the appointment of the Iranian Permanent Representative as the Rapporteur of the Policy Convergence on the HLPE report. This essentially blocked and delayed the actual implementation of the results, "undermining wellestablished and agreed-on procedures and protocols of the CFS" (Agroecology Working Group of the Civil Society Mechanism of the UN Committee on Food Security., 2019). Eventually, under pressure from other member states, the US conceded, and the rapporteur was able to advance the policy convergence.

Secondly, while the HLPE report ended up being clearly focused on the need to support agroecology and a food system transformation, the policy recommendations developed during the policy convergence watered down the messages of the report (Committee on World Food Security, 2020). While the HLPE report incorporated many points that would indeed support agroecology (e.g., shifting funds to agroecology research, supporting cooperatives, etc.), the overall call for food system transformations based on an agroecology approach were substantially diminished. The positioning of "agency" and rights was decentred. Where human rights are invoked, there aren't calls to guarantee or to enforce human rights, but rather to "recognize," "respect" or "promote" (Civil Society Mechanism for relations to the Committee on World Food Security (CSM), 2020). Further, despite a clear distinction in the HLPE report that agroecology was a vital approach that stands apart from "other innovations," the recommendations make generalized calls to support "agroecological approaches and other innovations." The policy recommendations thus continue to call for many of the business-as-usual approaches critiqued in the actual report, including approaches that "optimize agrochemical usage." It positions agroecology as a complimentary approach to tweaks to conventional agriculture, sustainable innovation, climate smart agriculture, and other approaches that were argued in the HLPE report to be largely incompatible.

Third, at a broader level, the strong assertation of a rights-based and food sovereignty-based agroecology prompted a strong back-lash by proponents of green revolution style agricultural development. For example, the USA Permanent Representative to the United Nations Agencies for Food and Agriculture in Rome Kip Tom has made claims that the FAO has been co-opted by European NGOs, "spreading mis-information" about GMOs and pesticides, and disparaging approaches to agriculture that don't conform to "American values." Using this platform he has made arguments for "the innovation imperative," which positions "progress and innovation as obvious goods" which he describes as the acceptance of American values and technologies (Tom, 2020). In similar move, the Gates Foundation-funded "Cornell Alliance for Science," whose main mission is to promote biotechnology in Africa, has also attacked agroecology as anti-science and irrational, claiming that it denies farmers the rights to access innovations, and in contrast, adopts an individualistic market-centered approach to rights (Conrow, 2020).

Finally, In October 2019, the UN Secretary-General's official announced a World Food Systems Summit to be held in New York in 2021. This major global summit aims to secure global 


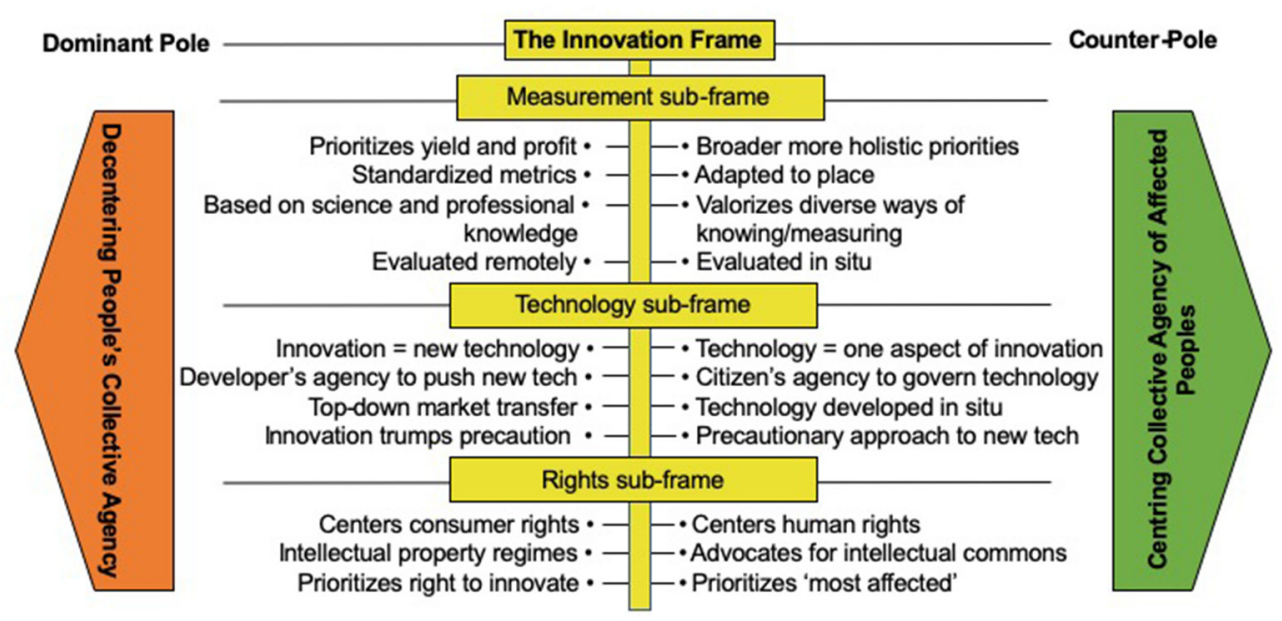

FIGURE 1 | The sub-frames of the innovation frame have both a "counter-pole" that centers the collective agency of people and a dominant pole that decenters people's collective agency.

commitments to address hunger, diet-related health and the environment. It is to be led by the World Economic Forum and has been widely critiqued for choosing a champion of biotechnology to chair the event. Although there are references to "multi-stakeholder" participation, the role of civil society and the issue of human rights have been effectively marginalized (Fakhri, 2020). Such events combine to remind us that while progress can be made shaping particular discursive arenas, the broader discursive landscape must also be considered. Indeed, more than simply being hostile, gains within specific discursive arenas can even prompt significant backlashes in the external environment. At time of writing the extent and impact of this 'reaction' remains to be seen.

\section{CONCLUSIONS}

Agroecology is being presented as an alternative vision of food and farming and, indeed, is gaining traction in local, national and global discourse. It is, however, a hotly contested term and its meaning and potential is being constructed through the interactions of a wide range of actors with different political agendas. Our study probed the ways that the innovation frame was mobilized in the United Nations debates on agroecology. We found that innovation can serve to contain and co-opt the transformative potential of agroecology (Anderson et al., 2019), and was intentionally mobilized by detractors of agroecology for that very purpose.

Although the ecological principles that underlie agroecology are critical, it is the emphasis on the collective knowledge, rights and agency of the most affected that separates agroecology from production-oriented proposals like climate smart agriculture and sustainable intensification (Pimbert, 2017). As a perspective rooted in the logic of increased production and technological modernization, our study showed how the innovation frame routinely overlooks and diminishes the social agency of individuals and communities-or as the HLPE themselves define it, the ability to, "define their desired food systems and nutritional outcomes, and to take action and make strategic life choices in securing these" (HLPE, 2019).

We identified three sub-frames of the innovation frame that played out in the discursive arena of the FAO. These focused on innovation in relationship with: evidence; technology; and rights. Within each of these sub-frames, it is clear that there were competing poles which can be understood through the lens of agency. On the one end, innovation is used to reinforce dominant conceptions of agency-overwhelmingly those exercised by individuals through markets-in ways that maintain the political status quo. On the other pole, proponents of agroecology put forward a counter-discourse for the collective rights and agency of the "most affected" as the basis for agroecological innovation (Figure 1). The agroecological approach challenges many of the assumptions that are bound up in the innovation imperative including: the centrality of agribusiness, the hegemony of abstract indicators, the notion that technology is the most important form of innovation and the casting of food producers as endusers or consumers. Centring the collective protagonism, voice, agency and autonomy of food producers and their communities in decision-making on the governance of food systems is a radical shift that is by in large side-lined by the innovation imperative.

The role of the innovation frame in undermining collective agency, and thus the political aspects of agroecology, might not be that surprising given its "Schumpeterian" origins and linked innovation systems in capitalist and neoliberal economics. The word innovation is used by many different actors for contrasting purposes, yet over almost a century of common usage, the term has become the friendly face of aggressive competition and freewheeling technological modernization. The innovation framing has consistently foregrounded the advantages to be gained by inventors, innovators, and intellectual property rights holders, while downplaying or masking the often-dire social and ecological consequences of technology, largely borne by the most disadvantaged. This dynamic continues to play out in deleterious 
ways in global food systems and beyond. To this end, we recommend that advocates of agroecology-and other holistic, political, and radical proposals for change-avoid the innovation frame in debates on policy, research, and visioning for the future, wherever possible. Where it is unavoidable, understanding the discursive dynamics across the sub-frames outlined in this article (Figure $\mathbf{1}$ for summary) can help understand, contest, and propose alternatives to the problematic dominant framing typical of mainstream innovation discourse.

Like sustainable agriculture, organics, and other related terms that have had their day in the sun as candidates for framing transformative change in the food system, the transformative thrust of "agroecology" is not a given. In many cases, concepts that have been initiated in a transformative perspective become warped and re-molded as they gain prominence and institutional uptake. This article highlights the framing of agroecology innovations as a potential strategy for undermining collective politics and the reassertion of a market fundamentalism. Recentring collective agency as the basis for evaluating innovations is a seemingly subtle, but vital, discursive maneuver being led by social movements, and a strategy that has already led to important outcomes in the FAO for agroecology. While recent attacks on agroecology outside the HLPE discursive arena should cause real concern, substantial gains have been made to bring radical arguments into these institutional spaces and to make both discursive and material gains as a result.

Innovation-often framed as novel technologies, transferred to users, to increase yield and profit-is an imperative only from the perspective of those fastened to the treadmill of

\section{REFERENCES}

Agroecology Working Group of the Civil Society Mechanism of the UN Committee on Food Security. (2019). Worldwide Civil Society Organizations Denounce US Government Obstruction of the UN Committee on World Food Security (CFS) Policy Convergence Process for Solutions to Food Security and Nutrition Crisis. Available online at: https://www.iatp. org/documents/worldwide-civil-society-organizations-denounce-usgovernment-obstruction-un-committee-0 (accessed February 2, 2021).

Anderson, M. (2020). "Innovation for whom," in Transformation of our Food Systems, eds H. R. Herren, B. Haerlin and IAASTD+10 Advisory Group (Berlin/Zurich: Zukunftsstiftung Landwirtschaft/Biovision), 33-36.

Anderson, C. R., Bruil, J., Chappell, M. J., Kiss, C., and Pimbert, M. P. (2019). From transition to domains of transformation: getting to sustainable and just food systems through agroecology. Sustainability 11:5272. doi: 10.3390/su11195272

Anderson, C. R., Pimbert, M., Chappell, M. J., Brem-Wilson, J., Claeys, P., Kiss, C., et al. (2020a). Agroecology now - connecting the dots to enable agroecology transformations. Agroecol. Sustain. Food Syst. 44, 561-565. doi: 10.1080/21683565.2019.1709320

Anderson, C. R., Bruil, J., Chappell, M. J., Kiss, C., and Pimbert, M. P. (2020b). Agroecology Now! Transformations Towards More Just and Sustainable Food Systems. Cham: Palgrave MacMillan.

Baker, S., and Mehmood, A. (2015). Social innovation and the governance of sustainable places. Local Environ. 20, 321-334. doi: 10.1080/13549839.2013.842964

Barrett, H., and Rose, D. C. (2021). Perceptions of the fourth agricultural revolution: what's in, what's out, and what consequences are anticipated? Sociol. Ruralis. 1-28. doi: 10.1111/soru. 12324 expensive and privately-owned technologies. In this article, we intended to unveil the oft-hidden politics which lies beneath the language of innovation, and the power and erasure that occurs through the demands of the "innovation imperative." Whereas, agroecology has been advanced as a radical alternative to industrial agriculture, the innovation discourse often undermines its potential. A more pressing imperative today is to adopt a language and practice that enables us to escape from the discursive and material hold of industrial agriculture. These political discursive strategies and struggles are one key aspect of the desperately needed societal transformations that foreground the collective rights and agency of food producers and citizens ahead of the profit motive.

\section{DATA AVAILABILITY STATEMENT}

Publicly available datasets were analyzed in this study. This data can be found at: http://www.fao.org/fsnforum/cfs-hlpe/ discussions/agroecology_innovation-v0.

\section{AUTHOR CONTRIBUTIONS}

Both authors contributed equally to the analysis and authorship of this article.

\section{FUNDING}

This research was supported by a grant from the British Academy (pf170070).

Bellwood-Howard, I., and Ripoll, S. (2020). Divergent understandings of agroecology in the era of the African green revolution. Outlook Agric. 49, 103-110. doi: 10.1177/0030727020930353

Berthet, E. T. A., Barnaud, C., Girard, N., Labatut, J., and Martin, G. (2015). How to foster agroecological innovations? A comparison of participatory design methods. J. Environ. Plan. Manag. 59, 280-301. doi: 10.1080/09640568.2015.1009627

Brand, S. (2010). (eds.). Whole Earth Discipline. New York, NY: Penguin.

Civil Society Mechanism for relations to the Committee on World Food Security (CSM). (2020). Zero Draft of the Policy Recommendation on "Agroecological and other innovative approaches" CSM's Comments (Rome).

Committee on World Food Security. (2020). Zero Draft of Policy Recommendations on Agroecological and Other Innovative Approaches for Sustainable Food Systems that Ensure Food Security and Nutrition. Rome: CFS.

Conrow, J. (2020). Agroecology must be based in reality, not romanticism, panelists. Cornell Alliance Sci. Available online at: https://allianceforscience. cornell.edu/blog/2020/10/agroecology-must-be-based-in-reality-notromanticism-panelists-agree/

El Bilali, H. (2019). Innovation-sustainability nexus in agriculture transition: case of agroecology. Open Agric. 4, 1-16. doi: 10.1515/opag-2019-0001

El Bilali, H. (2018). Relation between innovation and sustainability in the agrofood system. Italian J. Food Sci. 30, 200-225. doi: 10.14674/ijfs-1096

Fairclough, N. (2013). Critical Discourse Analysis: A Critical Study of Language. London: Routledge.

Fakhri, M. (2020). Agenda Item 3 A/HRC/46/33. Special Rapporteur on the Right to Food Report to the Human Rights Council. Available online at: https://undocs.org/Home/Mobile?FinalSymbol=A\%2FHRC\%2F46\%2F33\& Language $=E \& D e v i c e T y p e=$ Desktop $($ acceassed December 24, 2020). 
FAO (2016). Proceedings of the FAO International Symposium on the Role of Agricultural Biotechnologies in Sustainable Food Systems and Nutrition. Rome: FAO.

FAO (2018). Catalysing Dialogue and Cooperation to Scale up Agroecology: Outcomes of the FAO Regional Seminars on Agroecology. Rome: FAO.

FAO (2020). Our Priorities: The FAO Strategic Objectives. Rome: FAO.

Foucault, M. (1969). The Archaeology of Knowledge. Paris: Éditions Gallimard.

Fouilleux, E., Bricas, N., and Alpha, A. (2017). 'Feeding 9 billion people': global food security debates and the productionist trap. J. Europ. Public Policy 24, 1658-1677. doi: 10.1080/13501763.2017.1334084

Fuchs, D., and Glaab, K. (2011). Material power and normative conflict in global and local agrifood governance: the lessons of 'Golden Rice' in India. Food Policy 36, 729-735. doi: 10.1016/j.foodpol.2011.07.013

Garnett, K., Van Calster, G., and Reins, L. (2018). Towards an innovation principle: an industry trump or shortening the odds on environmental protection? Law Innovat. Technol. 10, 1-14. doi: 10.1080/17579961.2018.14 55023

Geels, F. W., Tyfield, D., and Urry, J. (2014). Regime resistance against low-carbon transitions: introducing politics and power into the multilevel perspective. Theory Culture Soc. 31, 21-40. doi: 10.1177/02632764145 31627

Giraldo, O. F., and McCune, N. (2019). Can the state take agroecology to scale? public policy experiences in agroecological territorialization from latin america. Agroecol. Sustain. Food Syst. 43, 785-809. doi: 10.1080/21683565.2019.15 85402

Giraldo, O. F., and Rosset, P. M. (2018). Agroecology as a territory in dispute: between institutionality and social movements. J. Peasant Stud. 45, 545-564. doi: 10.1080/03066150.2017.1353496

González de Molina, M., Petersen, P. F., Peña, F. G., and Capor, F. R. (2019). Political Agroecology: Advancing the Transition to Sustainable Food Systems. Boca Raton, FL: CRC Press.

Guthman, J. (2004). Agrarian Dreams: the Paradox of Organic Farming in California. Berkeley: University of California Press.

Hajer, M., and Versteeg, W. (2005). A decade of discourse analysis of environmental politics: achievements, challenges, perspectives. J. Environ. Policy Plann. 7, 175-184. doi: 10.1080/15239080500339646

HLPE (2018). Syhnthesis Report on VO Draft Consultation - Agroecological Approaches and Other Innovations for Sustainable Agriculture and Food Systems that Enhance Food Security and Nutrition. Rome: CFS High Level Panel of Experts.

HLPE (2019). Agroecological and Other Innovative Approaches for Sustainable Agriculture and Food Systems that Enhance Food Security and nutrition. Rome: CFS High Level Panel of Experts.

IAASTD (2009). Agriculture at a Crossroads: Report of the International Assessment of Agricultural Knowledge, Science, and Technology. Washington, DC: Library of Congress.

Joly, P. (2018). Note de Recherche IFRIS $N^{\circ}$ 6: Innovation and the Problem of Values. Paris: L'IFRIS.

Klerkx, L., and Rose, D. (2020). Dealing with the game-changing technologies of Agriculture 4.0: How do we manage diversity and responsibility in food system transition pathways? Global Food Security 24:100347. doi: 10.1016/j.gfs.2019.100347

Kothari, A., Salleh, A., Escobar, A., Demaria, F., and Acosta, A. (2019). Plurivers: A Postdevelopment Dictionary. New Delhi: Tulika Books.

Laforge, J. M. L., Anderson, C. R., and McLachlan, S. M. (2016). Governments, grassroots, and the struggle for local food systems: containing, coopting, contesting and collaborating. Agric. Human Values 34, 663-681. doi: 10.1007/s10460-016-9765-5

Lajoie-O'Malley, A., Bronson, K., van der Burg, S., and Klerkx, L. (2020). The future(s) of digital agriculture and sustainable food systems: an analysis of high-level policy documents. Ecosyst. Serv. 45:101183. doi: 10.1016/j.ecoser.2020.101183

Levidow, L., and Papaioannou, T. (2018). Which inclusive innovation? competing normative assumptions around social justice. Innov. Dev. 8, 209-226. doi: 10.1080/2157930X.2017.1351605

Levidow, L., Pimbert, M., and Vanloqueren, G. (2014). Agroecological research: conforming-or transforming the dominant agro-food regime? Agroecol. Sustain. Food Syst. 38, 1127-1155. doi: 10.1080/21683565.2014.951459
Loconto, A. M., and Fouilleux, E. (2019). Defining agroecology. Int. J. Sociol. Agric. Food 25, 116-137. doi: 10.48416/ijsaf.v25i2.27

López-García, D., Calvet-Mir, L., Di Masso, M., and Espluga, J. (2018). Multi-actor networks and innovation niches: university training for local agroecological dynamization. Agric. Human Values 36, 567-579. doi: 10.1007/s10460-018-9863-7

Marchetti, L., Cattivelli, V., Cocozza, C., Salbitano, F., and Marchetti, M. (2020). Beyond sustainability in food systems: perspectives from agroecology and social innovation. Sustainability 12:7524. doi: 10.3390/su12187524

Maughan, C., Anderson, C., and Kneafsey, M. (2020). A five-point framework for reading for social justice: a case study of food policy discourse in the context of brexit britain. J. Agric. Food Syst. Commun. Dev. 9, 1-20. doi: 10.5304/jafscd.2020.093.024

Méndez, V. E., Bacon, C. M., and Cohen, R. (2013). Agroecology as a transdisciplinary, participatory, and action-oriented approach. Agroecol. Sustain. Food Syst. 37, 3-18. doi: 10.1080/10440046.2012.736926

Meynard, J.-M., Jeuffroy, M.-H., Le Bail, M., Lefèvre, A., Magrini, M.B., and Michon, C. (2017). Designing coupled innovations for the sustainability transition of agrifood systems. Agric. Syst. 157, 330-339. doi: 10.1016/j.agsy.2016.08.002

Miles, C. (2019). The combine will tell the truth: on precision agriculture and algorithmic rationality. Big Data Soc. 6, 1-12. doi: 10.1177/2053951719849444

Moeller, N. I., and Devlaux, F. (2020). Finance for Agroecology: More Than Just a Dream? Brussels: CIDSE.

Montenegro de Wit, M., and Iles, A. (2016). Toward thick legitimacy: creating a web of legitimacy for agroecology. Elementa Sci. Anthropocene 4:000115. doi: 10.12952/journal.elementa.000115

Mummery, J., and Mummery, J. (2019). Transformative climate change adaptation: bridging existing approaches with post-foundational insights on justice. Local Environ. 24, 919-930. doi: 10.1080/13549839.2019.16 56180

Nyeleni (2015). Declaration of the International Forum for Agroecology. Available online at: http://www.foodsovereignty.org/forum-agroecology-nyeleni-2015/ (accessed January 25, 2021).

Nyeleni Movement for Food Sovereignty (2007). Nyéléni Declaration for Food Sovereignty. Available online at: http://nyeleni.org/spip.php?article290 (accessed January 25, 2021).

O'Brien, K. (2016). "Climate change adaptation and social transformation," in International Encyclopedia of Geography: People, the Earth, Environment and Technology, ed D. Richardson (Oxford: John Wiley \& Sons, Ltd), 1-8.

OECD (2015). The innovation Imperative: Contributing to Productivity, Growth and Well-Being. Paris: OECD.

Pansera, M., and Owen, R. (2018). Innovation and Development: The Politics at the Bottom of the Pyramid. Hoboken, NJ: John Wiley \& Sons.

Pimbert, M. (2017). Agroecology as an alternative vision to conventional development and climate-smart agriculture. Development 58, 286-298. doi: 10.1057/s41301-016-0013-5

Pimbert, M. P., and Moeller, N. (2018). Absent agroecology aid: on UK agricultural development assistance since 2010. Sustainability 10:505. doi: $10.3390 /$ su10020505

Quist, D. A., Heinemann, J. A., Myhr, A. I., Aslaksen, I., and Funtowicz, S. (2013). "Hungry for innovation: pathways from GM crops to agroecology," in Late Lessons from Early Warnings: Science, Precaution, Innovation, ed D. Gee (Brussels: European Environmental Agency), 458.

Rivera-Ferre, M. G. (2018). The resignification process of agroecology: competing narratives from governments, civil society and intergovernmental organizations. Agroecol. Sustain. Food Syst. 42, 666-685. doi: 10.1080/21683565.2018.1437498

Rosset, P. M., and Altieri, M. A. (2017). Agroecology: Science and Politics. Winnipeg: Fernwood.

Rover, O., de Gennaro, B., and Roselli, L. (2016). Social innovation and sustainable rural development: the case of a Brazilian agroecology network. Sustainability 9:3. doi: $10.3390 /$ su9010003

Schiller, K. J. F., Klerkx, L., Poortvliet, P. M., and Godek, W. (2019). Exploring barriers to the agroecological transition in Nicaragua: a technological innovation systems approach. Agroecol. Sustain. Food Syst. 44, 88-132. doi: 10.1080/21683565.2019.160 2097r 
Schumpeter, J. A. (2005). Business Cycles: A Theoretical, Historical, and Statistical Analysis of the Capitalist Process. Eastford, CT: Martino Publishing.

Scoones, I., Newell, P., and Leach, M. (2015). "The politics of green transformations," in The Politics of Green Transformations, eds I. Scoones, M. Leach, and P. Newell (London: Routledge), 19-42.

Seyfang, G., and Smith, A. (2007). Grassroots innovations for sustainable development: towards a new research and policy agenda. Env. Polit. 16, 584-603. doi: 10.1080/09644010701419121

Snow, D. A., and Benford, R. D. (1992). "Master frames and cycles of protest," in Frontiers in Social Movement Theory, eds A. D. Morris and C. M. Mueller (New Haven, CT: Yale University Press), 133-155.

Steinberg, M. W. (1998). Tilting the frame: considerations on collective action framing from a discursive turn. Theory Soc. 27, 845-872. doi: 10.1023/A:1006975321345

Stirling, A. (2014). From sustainability to transformation: dynamics and diversity in reflexive governance of vulnerability. SSRN 305-332. doi: $10.2139 / \mathrm{ssrn} .2742113$

Stuiver, M. (2006). "Highlighting the retro side of innovation and its potential for regime change in agriculture," in Between the Local and the Global (Research in Rural Sociology and Development. Vol. 12, eds T. Marsden and J. Murdoch (Bingley: Emerald Group Publishing Limited), 147-173.
Tom, K. (2020). Speech at U.S. Department of Agriculture's (USDA) 2020. Arlington, VA: Agricultural Outlook Forum.

Uphoff, N. (2013). Agroecological Innovations: Increasing Food Production with Participatory Development. New York, NY: Routledge.

Van Dyck, B., Kenis, A., and Stirling, A. (2019). "The GMO shall not be refused. talking back to the technosciences," in Historical Materialism Sixteenth Annual Conference (London).

van Hulst, F., Ellis, R., Prager, K., and Msika, J. (2020). Using co-constructed mental models to understand stakeholder perspectives on agro-ecology. Int. J. Agric. Sustain. 18, 172-195. doi: 10.1080/14735903.2020.1743553

Conflict of Interest: The authors declare that the research was conducted in the absence of any commercial or financial relationships that could be construed as a potential conflict of interest.

Copyright $\odot 2021$ Anderson and Maughan. This is an open-access article distributed under the terms of the Creative Commons Attribution License (CC BY). The use, distribution or reproduction in other forums is permitted, provided the original author(s) and the copyright owner(s) are credited and that the original publication in this journal is cited, in accordance with accepted academic practice. No use, distribution or reproduction is permitted which does not comply with these terms. 